\title{
A SENCIÊNCIA E O DIREITO DOS ANIMAIS
}

\author{
Marianna Machado Moraes ${ }^{1}$
}

\section{RESUMO}

O artigo trata da Senciência como fundamento para ampliação de direitos aos animais não humanos, uma vez que os humanos, independente de cognição ou de capacidade de agir são juridicamente protegidos pelo estado. O objetivo é demonstrar que é necessária uma reeducação e revolução social para que isso ocorra. Questiona-se se o animal não-humano necessita ser dotado de capacidades iguais as dos humanos para ter direitos morais e, por conseguinte, a mesma proteção legal, e se demonstra que o fato de não possuírem capacidades semelhantes à humana não os impede de ter tais direitos. Teorias filosóficas como de Peter Singer, Tom Regan e Hans Jonas são apresentadas para embasas a ideia central do artigo. A metodologia empregada no desenvolvimento desta pesquisa foi a pesquisa bibliográfica, realizada a partir da consulta a livros, artigos, jurisprudência e legislação que se dedicam ao estudo dos direitos dos animais não-humanos. Os resultados apresentados são os próprios avanços legislativos, bem como o próprio veganismo que se trata de um ato político.

Palavras-Chaves: Direitos dos Animais; Direitos Fundamentais; Senciência.

\begin{abstract}
The article deals with Sentience as a foundation for expanding the rights of non-human animals, since humans, regardless of cognition or ability to act, are legally protected by the state. The objective is to demonstrate that a re-education and social revolution is necessary for this to happen. It is questioned whether the non-human animal needs to be equipped with the same capacities as humans in order to have moral rights and, therefore, the same legal protection, and it is shown that the fact that they do not have human-like capacities does not prevent them from having such rights. Philosophical theories such as Peter Singer, Tom Regan and Hans Jonas are presented to support the central idea of the article. The methodology used in the development of this research was the bibliographic research, carried out through the consultation of books, articles, jurisprudence and legislation that are dedicated to the study of the rights of non-human animals. The results presented are the legislative advances themselves, as well as the very veganism that is a political act.
\end{abstract}

Keywords: Animal Rights; Fundamental Rights; Sentience.

\section{RESUMEN}

El artículo trata de Sentience como base para expandir los derechos de los animales no humanos, ya que los humanos, independientemente de su cognición o capacidad para actuar, están protegidos legalmente por el estado. El objetivo es demostrar que es necesaria una reeducación y una revolución social para que esto suceda. Se cuestiona si el animal no humano necesita estar dotado de las mismas capacidades que los humanos para tener derechos morales y, por tanto, la misma protección jurídica, y se demuestra que el hecho de que no tenga capacidades humanas no les impide tener tales derechos. Se presentan teorías filosóficas como Peter Singer, Tom Regan y Hans Jonas para apoyar la idea central del artículo. La metodología utilizada en el desarrollo de esta investigación fue la investigación bibliográfica, realizada a través de la consulta de libros, artículos, jurisprudencia y legislación que se dedican al estudio de los derechos de los animales no humanos. Los resultados presentados son los propios avances legislativos, así como el propio veganismo que es un acto político.

Palabras clave: Derechos Fundamentales; Derechos Animales; Sentience.

${ }^{1}$ Pós-graduada em Direito Público; mestranda em Ciência Política Jurídica. 


\section{INTRODUÇÃO}

O Direito é dinâmico, e sendo fruto das relações sociais, sofre substanciais alterações com o passar dos tempos, o que, por sua vez, provoca diversas mudanças na organização social e no modo como esta se comporta diante de determinados acontecimentos.

A legislação que protege os animais vem avançado ao longo dos tempos, mas o objetivo deste artigo é demonstrar que a senciência é um fundamento para a ampliação dos direitos dos animais, aqui chamados de animais não humanos, pois animais somos todos.

A senciência se traduz como a capacidade de sentir, de ser afetado de forma positiva ou negativa, de estar consciente, de possuir sistema nervoso que dá origem à consciência, o que torna crucial para a avaliação da moralidade e defesa da positivação de direitos fundamentais aos animais.

Contudo, quando se fala em ampliação de direitos aos animais há uma polarização de argumentos que oscilam entre o respeito ao sofrimento e à vida do animal não humano que está sendo utilizado e a necessidade absoluta da manutenção desse uso para servir aos interesses da ciência e dos animais humanos. Mas esta argumentação tão frequente, que faz parte do próprio discurso da ciência e de seus pesquisadores, paradoxalmente não tem fundamentação científica baseada em avaliações sistemáticas, revisões de trabalhos e de seus resultados. Só recentemente vêm sendo realizadas análises críticas sobre esses dados, com obtenção de resultados não favoráveis ao modelo tradicional.

Paralelamente, crescem os argumentos de ordem ética sobre a utilização de animais não humanos para benefício em prol da espécie humana. São usos e experimentos que causam sofrimento de diferentes graus até a morte. Assim, amplia-se a crítica às análises de base utilitarista demonstrando-se que mudanças estão ocorrendo em âmbito mundial no sentido de se atribuir direitos fundamentais aos animais não-humanos.

Apesar das diferenças entre culturas e países, as legislações que norteiam a proteção aos animais não humanos possuem pontos de convergência: a não consideração de capacidades dos animais não humanos, como por exemplo, a Senciência e a cognição, assim como a não consideração do sofrimento imposto 
aos animais em práticas diversas, a exemplo da experimentação. Há o reconhecimento de que tais práticas impõem sofrimentos diversos aos animais não humanos, mas o predomínio dos interesses humanos sobre os demais é notório.

\section{ESPECISMO: O PRECONCEITO VELADO}

Cada vez mais estudos no campo da etologia aprofundam o conhecimento da relação do animal não humano com o meio e da relação humano-animal. Pesquisas desenvolvidas na área neuro-cognitiva demonstram que animais de diferentes espécies como mamíferos, aves e alguns cefalópodes, como os polvos, possuem capacidades semelhantes ao homem, inclusive em termos de possuírem estruturas neurológicas semelhantes às humanas responsáveis por gerar a consciência. Pode-se questionar se 0 animal não humano necessita ser dotado dessas capacidades na mesma medida dos humanos para ter direitos morais e, por conseguinte, a mesma proteção legal. O fato de não possuírem capacidades semelhantes à humana não os impede de ter tais direitos, assim como ocorre com os humanos que não possuem capacidades dos demais indivíduos da espécie, que têm garantido um mesmo nível de proteção pelo simples fato de pertencerem à espécie humana, por vezes recebendo um nível mais elevado de proteção do ponto de vista social e legal, como caracteriza a noção de vulnerabilidade a eles aplicada.

Apresentamos elementos nos quais se evidenciam a possibilidade de um relacionamento interespécie e no qual a justiça beneficie todos os seres vulneráveis. Com teorias jurídicas, morais e políticas que acrescentam elementos para desenvolver uma revolução social por meio da qual seja possível um relacionamento interespécie guiado por princípios de justiça e pelo uso dos sistemas de proteção para beneficiar todos os seres.

Acredita-se que a consideração e a solidariedade entre os animais humanos podem ser estendidas a todos os animais a partir de uma educação moral ampliada, para que as relações interespécie dignas possam ser alcançadas, tendo a educação moral como base dos princípios da justiça. A garantia dos direitos positivos a nível estatal aos animais sencientes poderia se dar através de uma revolução ética, que já está em processo como se pode 
observar, e que se contínua, será possível uma justiça inclusiva - da qual o Estado deve ser o garantidor - rompendo paradigmas ainda existentes.

O especismo está compreendido como uma construção social que parece funcionar como um sistema em interação com as categorias que caracterizam o racismo, sexismo, xenofobismo, dentre outros tantos "ismos" e assente nas mesmas ideologias, em especial, a naturalização de categorias.

O preconceito se refere a "qualquer atitude, emoção ou comportamento em relação aos membros de um grupo, que direta ou indiretamente implique alguma negatividade ou antipatia em relação a esse grupo" (BROWN, 2010, p. 7). Diante disso, o especismo parece se encaixar, envolvendo crenças negativas, emoções e comportamentos em relação aos outros com base em seu pertencimento a um determinado grupo de espécies.

Peter Singer, a partir da obra Animal Liberation, publicada em 1975, transborda os limites do antropocentrismo e contraria, assim, o critério da espécie para a atribuição de dignidade a um ser. Com efeito, afirma que é "a capacidade de sofrimento como característica vital que concede a um ser 0 direito a uma consideração igual" (SINGER, 2008, p. 7). A capacidade de sofrer ou de estar feliz não depende da linguagem nem da razão, como equivocadamente supunha a ética tradicional. Nesse sentido, para o referido autor, "a capacidade de sofrimento e alegria é, no entanto, não apenas necessária, mas também suficiente para que possamos afirmar que um ser tem interesses - a um nível mínimo absoluto, o interesse de não sofrer" (SINGER, 2008, p. 7).

Por esta razão, é injustificável moralmente não se levar em consideração o sofrimento de um ser, pois, independentemente de sua natureza, o princípio da igual consideração exige que o seu sofrimento seja considerado tanto quanto o de outro ser capaz de semelhante sofrimento. Desse modo, a "Senciência"2 deve ser o único parâmetro para a preocupação justificável relativo aos interesses dos outros. Segundo Singer, "o estabelecimento deste limite através do recurso a qualquer outra característica, como a inteligência ou a racionalidade, constituiria uma marcação arbitrária" (SINGER, 2008, p. 8).

Singer (2008, p. 8) utiliza este termo para designar a capacidade de sofrer e/ou experimentar alegria, admitindo, contudo, fazê-lo por conveniência, e não por correção técnica. 
A partir desse raciocínio, e por analogia ao racismo, Peter Singer utiliza o termo "especismo" para designar um preconceito ou atitude de favorecimento dos interesses dos membros de uma espécie em detrimento dos interesses dos membros de outras espécies.

E, para pôr à prova o especismo reinante entre os humanos, Peter Singer analisa os assim chamados "casos marginais", ou seja, aqueles em que seres de espécies diversas, mas igualmente sem capacidade de razão, como os bebês, os adultos com problemas mentais e os animais não humanos, e, após considerá-los todos como pertencentes a uma mesma categoria, chega à seguinte instigadora conclusão:

[...] se o usarmos para justificar as experiências com animais, temos de nos perguntar se estamos preparados para admitir que sejam feitas as mesmas experiências com recém-nascidos humanos e adultos com graves deficiências mentais. Se fizemos uma distinção entre os animais e esses seres humanos, caberá também a pergunta: de que modo poderemos fazê-la, a não ser com base numa preferência moralmente indefensável por membros de nossa própria espécie? (SINGER, 2008, p. 70).

Hans Jonas (1995) traz uma proposta ética para a civilização tecnológica, ao mesmo tempo em que transcende a barreira do humano, não se limita à extensão da dignidade aos outros animais. Em verdade, sua formulação busca alcançar a natureza em geral, além das gerações presentes e futuras.

O ponto de partida da análise de Hans Jonas é a constatação de que a ética tradicional já não responde aos questionamentos necessariamente advindos da técnica moderna. Por outro lado, sabe-se que o homem sempre esteve ligado à natureza pela técnica. O que o autor precisa saber, e desenvolve seu trabalho com o fim de fazê-lo, é descobrir as razões que diferenciam a técnica contemporânea das anteriores. Com efeito, a técnica moderna tem introduzido ações de magnitude tão diferente, com objetos e consequências tão novas, que o marco da ética já não pode abarcar (JONAS, 1995, p. 32)

\section{SENCIÊNCIA E DORÊNCIA}

Richard Ryder restringe a amplitude conceitual do critério estabelecido por seu contemporâneo Peter Singer, o da "senciência", a servir de linha divisória 
entre os sujeitos dignos de consideração moral direta e aqueles em relação aos quais os deveres morais são apenas indiretos, e propõe o da "dorência", conforme tradução de Sônia Felipe. ${ }^{3}$

Como ficou pontificado, quando da abordagem do pensamento de Peter Singer, por "senciência" ele busca abarcar tanto a capacidade de sentir dor como a de sentir prazer. Este último aspecto, de sentir prazer, contudo, não deve ser, no entender de Richard Ryder, objeto de preocupação da ética, a qual deve se ocupar de um dever negativo, o de não Ihes causar dor ou sofrimento (FELIPE, 2004).

Desse modo, apesar da proximidade do critério da "dorência", de Richard Ryder, com o da "senciência", de Peter Singer, eles se distanciam porque o primeiro é mais restrito, limitando-se à capacidade de sentir dor e sofrer, ao passo que a "senciência", além da capacidade de sofrer, inclui a de sentir prazer. Além disso, segundo informa Daniel Lourenço (2008), o critério de Richard Ryder tem como parâmetro o sujeito passivo, individualmente considerado, e não a raça ou a espécie, razão por que, ao contrário do que faz Peter Singer, a dor não pode ser resultado de uma ponderação, de um balanceamento entre benefícios e prejuízos.(LOUREÇO, 2008). De fato, para Richard Ryder:

[...] a minha dor e a dor de outros estão compartimentalizadas de modo estanque, não se pode realizar operações de adição ou subtração entre elas. [...] Por exemplo, infligir cem unidades de dor a um indivíduo é, em minha opinião, bastante diferente e pior que infligir uma única unidade de dor em milhares ou milhões de pessoas, ainda que o total agregado de dor seja muito maior no último caso. Em qualquer situação, deveríamos nos preocupar primariamente com a dor do indivíduo que é o sofredor máximo (LOUREÇO, 2008, p.417).

Nesse sentido, e levando-se em conta que a dor torna o ser sensível incapaz de viver sua vida com plenitude, Ryder (apud LOUREÇO, 2008, p. 418) defende que o ser humano tem o dever de não causar sofrimento a outrem, dever este que correlaciona-se ao direito que terceiros têm de não passar por sofrimento ou sentir dor injustificadamente.

Tom Regan (2006), em seu livro Jaulas Vazias, defende que se trata de um desafio a defesa de que detém os animais direitos, vez que são sujeitos-de-uma-

FELIPE, Sônia T. Produção de animais: a crítica filosófica abolicionista. [Em linha]. Texto da conferência proferida no $36^{\circ}$ Congresso Vegetariano Mundial, realizado no Costão do Santinho, Florianópolis/SC, em 09.11.2004. [Consult. em 30 Dez. 2020]. Disponível em: <http://www.vegetarianismo.com.br/artigos>. 
vida. Regan (2006) apresenta novos critérios e reivindicações precisas quanto ao tratamento ofertado aos animais, fazendo parte de um novo grupo de defensores dos animais.

Algumas perguntas devem nortear a análise da teoria por ele apresentada, como: no que a tese de Singer se diferencia da tese de Regan (2006) e quais as consequências mais expressivas do acolhimento da tese reganiana? Estas duas análises, uma vez objetivamente consideradas, serão capazes de direcionar a constatação principal: no que consistiria a defesa dos direitos animais para Tom Regan?

Apresenta-se de forma genérica, sem perder a noção de essencialidade, os principais pontos de sustentação do pensamento reganiano.

Thomas Howard Regan nasceu no Estado da Pennsylvania, estudou filosofia na década de 60 e, nos idos de 1975, elaborou um inusitado artigo sobre os direitos dos animais, intitulado "A moral básica do Veganismo", apresentando ao mundo acadêmico, um ano depois, uma coletânea de artigos sobre a moral dos animais, em parceria com Peter Singer.

A principal defesa de Regan (2006) consiste em apresentar que os direitos dos humanos não se opõem aos direitos dos animais não humanos ao admitir uma teoria moral que a todos assistem direitos, sejam humanos ou não humanos.

A alusão à existência de direitos para os animais, realizada por Regan, demonstra uma clara modificação no perfil dos interesses a serem protegidos pelas correntes filosóficas em favor dos animais.

Regan, como filósofo, reconhece, ao apresentar em sua obra, a existência de uma moral que sustenta os direitos dos animais e afirma que isto se trata de uma ideia simples, mas também profunda (FERREIRA, 2014, p. 79). Sabe-se que o sistema jurídico, na alusão de Orlando Gomes, constitui uma coordenação dos diversos institutos jurídicos em um todo harmônico (GOMES, 2007, p. 13), elevando-se, em especial, sua função social, caracterizada em razão de elementos teleológicos e estruturais.

\section{DO PONTO DE VISTA JURÍDICO}

Pontes de Miranda, no ano de 1928, lançou a obra "Fontes e Evolução do 
Direito Civil Brasileiro", e em suas primeiras páginas constatou a necessidade de evolução social e da função social do direito. Nas suas conjecturas, defende 0 renomado Jurista a necessidade de adaptar as normas legais às novas demandas e realidades, como reflexo da evolução ou, em caso contrário, de retrocesso social.

Ciente da necessidade de adequar as leis às mudanças que ocorrem na sociedade, importa discutir sobre a possível repercussão da prescrição contida na Constituição Federal de 1988, em seu artigo 225, $\S 1^{\circ}$, VII, pela qual os adeptos do Direito Animal reclamam a constatação de estar nele insculpido um direito fundamental, de forma a conduzir no sistema jurídico um papel orientador de novas condutas e necessária alteração do status jurídico dos animais, passando-se de bens a sujeitos de direito.

Orlando Gomes (2007) sinaliza que o estudo da relação jurídica assumiu uma função nuclear na Teoria Geral do Direito, tendo em vista que o mesmo deixou de ser desenvolvido em função do sujeito, para, então, gravitar em torno do conceito de relação jurídica.

Evidente, portanto, que a transformação de um vínculo comum em um vínculo jurídico requer que, sobre aquele, incida uma norma jurídica. A relação jurídica é marcada por dois atributos fundamentais, quais sejam: a bilateralidade, concernente na correlação entre direitos e deveres, bem como a reciprocidade, que significa que ninguém poderá agir em relação a outrem sem dar-lhe também a possibilidade de agir de forma análoga.

Gomes (2007) sustenta, ainda, que o Direito possui dois traços distintivos dos demais sistemas normativos, são eles a alteridade e a exterioridade. Uma relação jurídica, para este Jurista, é traçada entre dois ou mais sujeitos de direito, denominados "partes". Estas, por sua vez, diferenciam-se dos terceiros, que são sujeitos alheios àquela relação jurídica, no entanto podem ter interesses nos efeitos e/ou consequências daquele vínculo. Desta forma, relata o autor que a relação jurídica pode se mostrar complexa, gerando diversos direitos e deveres interligados, ou simples, quando importa em direitos apenas para uma parte e deveres para outra.

Rodrigues (2012) defende que o sujeito da relação jurídica é sempre o homem e que, ao se ver em uma relação jurídica na presença de organismos que não sejam humanos, como o são as pessoas jurídicas, é resguardado, em 
verdade, o interesse humano.

No entendimento de Gordilho e Trajano (2012, p. 350), os sujeitos de direito em dois grupos: sujeitos personificados/despersonificados e corpóreos/incorpóreos. Cabe a ressalva apenas de que existem sujeitos com atributos próprios que os tornam "pessoas" e há também aqueles que não são pessoas. Assim, para os autores, as ideias de personalização não é uma condição para que se tenha direitos, nem obriga a qualquer prestação, vez que aos sujeitos despersonalizados também são atribuídos certos direitos e deveres (GORDILHO; TRAJANO, 2012, p. 350).

Para os que defendem essa teoria, o conceito de pessoa é apenas uma construção cultural, ele não é dado de maneira natural, motivo pelo qual existem as pessoas naturais e as jurídicas. Enfatizam que no passado, as mulheres, crianças e escravos também não tinham personalidade jurídica. Em meio àqueles que defendem o direito de personalidade aos animais não humanos há uma corrente mais radical denominada "anti-especismo", que defende o reconhecimento da igual consideração dos interesses animais e equipara a discriminação animal ao racismo (GODINHO; GODINHO, 2011). As críticas feitas à personificação ocorrem por diversas razões:

Se, por um lado, é incongruente afirmar que os animais são titulares de direitos - sejam eles extrapatrimoniais, como os direitos fundamentais e da personalidade, sejam os de caráter patrimonial, já que não se concebe como eles poderiam celebrar negócios jurídicos e amealhar, administrar ou partilhar bens -, por outro lado, é ainda mais pitoresca a hipótese de imaginá-los dotados de obrigações na ordem civil. Mais ainda, noutras searas do Direito, como o Penal, seria absurdo propor que animais pudessem ser sujeitos ativos ou passivos de crimes. Se os animais se tornassem pessoas, entes com capacidade de assumir direitos e contrair obrigações, em tese deveriam responder por seus atos que eventualmente causassem dano a outrem, o que dispensaria a aplicação do artigo 936 do Código Civil brasileiro, que imputa ao proprietário do animal (o verdadeiro sujeito de direitos) a responsabilidade objetiva pelos danos causados por este. Já no polo passivo dos ilícitos penais, seria homicídio matar um animal, ainda que para fins de consumo, já que, ao se tornar pessoa, este deixaria de ser "algo" para se tornar "alguém", tipificandose, assim, o delito previsto pelo artigo 121 do Código Penal brasileiro? Configuraria crime de omissão de socorro, com notáveis requintes de crueldade, deixar de salvar a vida de uma mosca pousada na sopa, à beira da morte por afogamento? Afinal, apesar de o exemplo tangenciar o ridículo, não se pode deixar de afirmar que, na hipótese, deixa-se de prestar assistência a uma pessoa em grave e iminente perigo de vida, fato que corresponde ao tipo penal em apreço (GODINHO; GODINHO, 2011). 
Também a CRFB/1988 promoveu, por seu artigo 225 a proteção da fauna e da flora. Assim, destina aos animais um estatuto diferente daquele que é destinado às coisas, fato que não induz obrigatoriamente ao reconhecimento de que os animais são seres personificados, pois nos dizeres de Godinho e Godinho (2011) caso os animais sejam considerados sujeitos de direitos, não poderão ser considerados, objetos de direito.

Observe-se que, tanto Gordilho e Trajano (2012) como Godinho e Godinho (2011) sugeriram que fosse criado um terceiro gênero, o gênero dos animais, distinto das categorias de pessoas e coisas. Segundo os autores, essa solução tem como benefícios: a de não reconhecer que os animais são meras coisas, destinar-Ihes um regime jurídico próprio e não mais haver a necessidade de conceder-Ihes personalidade jurídica. Porém, este posicionamento também recebe críticas.

Segundo Daniel Lourenço (2008, p. 44), os direitos da personalidade podem ser distribuídos em cinco núcleos centrais: vida, integridade física, honra, imagem, nome e intimidade. Cumpre ratificar que não apenas as pessoas naturais possuem tais direitos, mas conforme já confirmado pelo Superior Tribunal de Justiça (STJ), a teor da súmula 226, as pessoas jurídicas têm esses direitos assegurados, naquilo que for cabível. Neste contexto, defende Lourenço que, ao lado de outros sujeitos que foram reconhecidos pelo Direito, os animais poderiam ser inseridos na categoria de "entes despersonalizados não humanos" (LOURENÇO, 2008, p. 44) com a ressalva de que tal chancela normativa se dá em razão da necessidade da defesa dos seus interesses.

O reconhecimento dos animais como entes despersonalizados não humanos oportunizaria a defesa processual adequada aos mesmos, que apesar de desprovidos de personalidade jurídica, poderiam se valer de instrumentos jurídicos para a garantia de um mínimo existencial.

Existem direitos que nascem com cada indivíduo, são direitos naturais, como o direito à vida, a liberdade, à maternidade e tantos outros que são imutáveis e inerentes aos seres vivos. A sociedade necessita do Estado para que organize um conjunto de normas jurídicas de amparo a esses direitos, para que não sejam objeto de violação, garantindo-se uma proteção integral.

Apesar das garantias pelo Estado à proteção dos direitos naturais que ora

Tendências Multidisciplinares: Investigação, Método e Ciência 
restam positivados, Carvalho (2016) afirma que as normas constitucionais, sua interpretação e concretização espelham os valores básicos da sociedade e como a relação do homem com os animais não humanos é complexa e contraditória, não é surpreendente que as normas jurídicas também o sejam.

Ernandorena ${ }^{4}$ explica que no Brasil, só em meados do Século XX teve início o processo de reconhecimento dos direitos dos animais não humanos, que encontrou seu clímax na CRFB/1988. Afirma o autor que é flagrante o descompasso da legislação brasileira em face do direito das nações mais avançadas e da percepção de grande parte da sociedade em relação aos seres não humanos, implicando na necessidade de atualização da legislação, para além da postura conservadora do Congresso Nacional a respeito da matéria ainda que se tenha presente que a lei, por si só, não se constitua numa resposta absoluta.

Mas, antes de abordar sobre tais contradições, é importante evidenciar que o estudo sistemático sobre a natureza ganhou um maior número de adeptos somente no século XIX, porém, foi no século XX que se passou a observar maior produção legislativa no Brasil em defesa da causa animal.

Silvestre (2018, p. 57) aponta que especialmente com a promulgação da CRFB/1988 o texto passou a prever a proteção da fauna e a vedação da crueldade contra os animais não humanos. Nesse sentido, a Constituição deixou de reconhecer a proteção dos animais tão-somente como uma garantia para um meio ambiente ecologicamente equilibrado, legitimando o dispositivo como uma norma autônoma, garantindo, dessa forma, que os animais não devem ser relegados à simples condição de elementos ambientais.

A relação entre homem e natureza é fundamental. A vida dos animais relaciona-se à do homem, pois vivem em equilíbrio dinâmico com o meio e a ele reagem de forma individual.

O ordenamento jurídico brasileiro considera os animais ora como objetos passíveis de comporem o patrimônio privado, ora como bens socioambientais, tratando da matéria dentro dos direitos coletivos; logo, com titularidade 
indeterminada. $^{5}$

Mediante a introdução do $\S 1^{\circ}$ no inciso VII do artigo 225, a CRFB/1988 incumbiu ao Poder Público e à coletividade a proteção da fauna, sendo que a competência para legislar é concorrente da União, Estados e Municípios, conforme o disposto nos artigo 24, inc. VI, 30, incisos I e II e 23, inc. VII.

Contudo, o império das legislações protetoras dos animais submete-se à visão antropocêntrica, sempre em primazia do ser humano. Machado ressalta que "a tutela estatal sobre a fauna silvestre tornou clara a sua existência como bem ambiental de valor econômico" (MACHADO, 2016, p. 730).

Embora sejam os animais sujeitos com personalidade jurídica autônoma, de acordo com a interpretação do Decreto-lei 24.645/34, a legislação civil ainda não foi aperfeiçoada. Tanto o Código Civil Brasileiro de 1916 como Código Civil de $2002^{6}$ definem os animais como coisas sem dono até momento de sua apropriação, valendo-se de um tratamento privatista a apoiar o instituto da propriedade.

Até os dias de hoje os animais continuam vistos como coisas ou semoventes disponíveis; mesmo a Lei de Proteção à Fauna tenha alterado sua natureza jurídica de coisas sem dono para bens públicos, como é o caso dos animais silvestres fora do cativeiro, cujo ordenamento é a utilidade pública, e a CRFB/1988 para bens socioambientais. De qualquer maneira, se antes considerados sob o regime privado, atualmente alguns o são sob o regime público, porém em ambos, sob a ótica de objeto de direito e não sujeito de direito.

Assim, não obstante o sistema jurídico tenha resistido em reconhecer, é inconteste a posição de que os animais têm direitos inerentes e próprios dos seres vivos sencientes. É preciso haver uma ética mínima universal.

É necessário, pois, estabelecer o modo humano adequado de agir, com fundamento em valores fundamentais que devem envolver o atual paradigma

Nesse sentido, Souza Filho elucida: "Todo o bem socioambiental tem pelo menos duas expressões jurídicas e comportam, assim, dupla titularidade. A primeira é do próprio bem, materialmente tomado; a segunda é a sua representatividade, evocação, necessidade ou utilidade ambiental e a relação com os demais, compondo o que a lei brasileira chamou de meio ambiente ecologicamente equilibrado. As duas não se excluem, ao contrário se complementam e se subordinam na integralidade do bem, como se fossem seu corpo e sua alma" (SOUZA FILHO, C.F.M. Introdução ao direito socioambietal. In: O direito para o Brasil sócio-ambiental, 2002. p. 41 apud CAVALCA, R.F. O Direito Constitucional Internacional e os animais: a tutela dos animais como sujeitos de direitos. In: GARCIA, M; GAMBA, J.C.M; MONTAL, Z.M.C. (Coords.). Direito Constitucional Internacional. Curitiba: Juruá Editora, 2012, p. 379.

6 Por interpretação dos arts. 47, 594 a 598; 781 a 788; 1.416 a 1.423 e 1.527 do Código Civil de 1916 e arts. 82 e 1.263; 1.442 a 1.477 e 936 do Código Civil de 2002. 


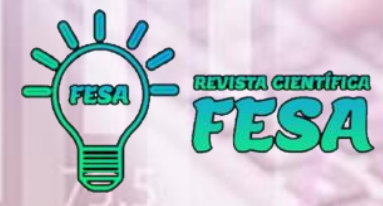

social. Para lograr êxito na preservação da vida dos animais, importa constatar a obrigação de uma profunda mudança na mentalidade do homem, a moldar sua consciência e atitude críticas sobre o frágil equilíbrio da natureza e da singularidade da vida.

Impende uma maior reflexão sobre a "coisificação" não apenas da natureza, como também dos animais, com vistas a fazer surgir um plano global de ações para preservar seus essenciais direitos.

No entanto, a lei não estabelece os direitos coletivos, e os animais permanecem sob a velha ótica. Dessarte, a inadequação da natureza jurídica dos animais demonstra que o ordenamento jurídico é incompleto, pois não os compreende como bens públicos, tampouco privados. Sequer há determinação legal sobre o reconhecimento de seus direitos.

Considerando-se a biodiversidade, ao incluir os animais, estes são bens socioambientais, de suma importância para a manutenção da vida de todos os seres vivos, passam a imperar os direitos socioambientais. Esses, além de fortalecerem uma nova postura filosófica diante da vida, por serem indivisíveis, proíbem que os bens estejam disponíveis aos proprietários e permitem a intervenção do Estado na propriedade privada, assim como na ordem econômica (CAVALCA, 2012, p. 381).

Os animais, mesmo que não todos, passaram a ser tutelados mediante essa perspectiva e, para tanto, foram edificadas normas referentes às unidades de conservação, reservas e estações ecológicas, áreas de proteção ambiental, enfim, todas que têm o objetivo de proteger os ecossistemas da fauna e flora em lei regulamentadas.

Segundo Ackel Filho (2001, p. 64), ao analisar a natureza jurídica dos animais, constata-se que ainda não houve reconhecimento do status quo como sujeitos de direitos, a despeito do disposto no $\S 3^{\circ}$ do artigo $3^{\circ}$ do Decreto $n^{\circ}$ 24.645/1934, o qual estabelece a representação dos mesmos em juízo pelo Ministério Público. No entanto, esse dispositivo por si só tem importância em concepção sobre a natureza jurídica dos animais. ${ }^{7}$

\footnotetext{
A propósito, Ackel assegura que "já se pode afirmar que a norma atribui aos animais uma espécie de personificação, que os torna sujeitos de direitos dos quais podem gozar e obter tutela jurisdicional em caso de violação. Pode-se sustentar que os animais constituem individualidades dotadas de uma personalidade típica à sua condição. Não são pessoas, na acepção do termo, condição reservada aos humanos. Mas são sujeitos titulares de direitos civis e constitucionais, dotados pois, de uma espécie de personalidade sui generis, típica e própria à sua condição" (ACKEL FILHO, D. Direito dos animais. São Paulo: Themis, 2001, p. 64).
} 


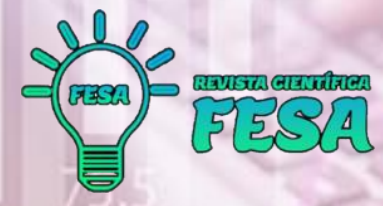

Mai. 2021

v. 1, n. $4,03-19$

ISSN: 2676-0428

Ackel bem observa que os animais são "seres biopsicológicos titulares de direitos fundamentais e como tais considerados, no campo jurídico, como sujeitos especiais, como elementos de personificação anômala e não como coisas semoventes" (ACKEL FILHO, 2001, p. 68).

O positivista Hans Kelsen (2000), em sua obra Teoria Geral do Direito e do Estado, reacendeu os debates sobre o conceito de pessoa, concluindo que a pessoa física não é uma realidade natural. ${ }^{8}$

\section{CONSIDERAÇÕES FINAIS}

Nesse trilhar, se para o direito a ideia de ser pessoa não implica necessariamente o ser homem, mas sim, o ser apto a ser titular de direitos e deveres; os animais que são substituídos pelo Ministério Público ${ }^{9}$ estariam necessariamente inclusos nessa ótica.

Destarte, sabendo-se que todo titular de relações jurídicas é também sujeito de direito, resta claro que a noção de sujeito de direito não implica na ideia de ser indivíduo (KELSEN, 2000, p. 140) e, neste trilhar, podem os animais, como titulares de relações jurídicas, ser considerados sujeitos de direito e então seriam naturalmente incluídos na categoria de pessoas, mesmo que segundo o predicado terminológico não sejam pessoas físicas ou jurídicas.

O importante e essencial é assegurar aos animais uma tomada de consideração jurídica: um estatuto jurídico definido pela lei. Finalmente, é preciso

\footnotetext{
Segundo Hans Kelsen, a pessoa é "uma elaboração do pensamento jurídico. Assim é que: definir a pessoa física (natural) como um ser humano é incorreto, porque homem e pessoa não são apenas dois conceitos diversos, mas também os resultados de dois tipos inteiramente diversos de consideração. Homem é conceito da biologia e da fisiologia, em suma, das ciências naturais. Pessoa é um conceito da jurisprudência, da análise de normas jurídicas" (KELSEN, H. Teoria Geral do Direito e do Estado. Tradução de Luís Carlos Borges. 3. ed. São Paulo: Martins Fontes, 2000, pp. 139-140). E apregoa que "pessoa é uma construção da dogmática jurídica, traduzida pela unidade personificada das normas sobre a gama de complexos direitos e deveres da pessoa natural ou jurídica. Sob o ponto de vista natural, pessoa é o ser humano, e na construção abstrata do Direito, é o ser dotado de personalidade jurídica, capaz de ser titular de direitos e obrigações" (KELSEN, H. Teoria Geral do Direito e do Estado. Op. cit., p. 140).

9 No ano de 2005, o Ministério Público do Estado da Bahia, por meio de seus Promotores de Justiça, Dr. Heron José de Santana e Dr. Luciano Rocha Santana, em conjunto com diversos professores e organizações não governamentais, impetraram o Habeas Corpus 833085-3-2005 (com pedido liminar), em favor de "Suíça", uma chimpanzé que se encontrava aprisionada no Parque Zoobotânico Getúlio Vargas, numa jaula com área total de 77,54 metros quadrados. Na ampla fundamentação do mandamus, demonstrou-se a necessidade da extensão dos direitos humanos aos grandes primatas, bem como a evidente precariedade das condições nas quais era mantida a chimpanzé, animal sabidamente sociável que necessita de variados recursos para a garantia de seu bem-estar físico e mental; Com essa motivação, pediu-se a concessão da ordem em favor do animal para que fosse determinada sua soltura e imediata transferência para o Santuário dos Grandes Primatas do GAP, em Sorocaba/SP, cuja direção já havia inclusive disponibilizado o transporte para a remoção. O juiz, Dr. Edmundo Cruz, titular da 9a Vara Criminal de Salvador/BA, apesar de indeferir a concessão da liminar requerida, deu curso ao processo intimando a autoridade coatora a prestar as informações cabíveis. Infelizmente, antes do julgamento do mérito da impetração, "Suíça" veio a falecer, solitária, em sua jaula, o que conduziu à perda do objeto do Writ. No entanto, devem ser salientadas as acertadas ponderações do magistrado por ocasião da sentença: "Pode ou não pode um primata ser equiparado a um humano? Será possível um animal ser liberado de uma jaula através de uma ordem de Habeas Corpus?" (LIMA, M.P. Curso de direito processual penal. 2. ed. Rio de Janeiro: LumenJuris, 2006. p. 290)
} 
notar que a Carta Mundial da Natureza, recepcionada pela Assembleia Geral das Nações Unidas, em 28.10.1982, que traduz uma filosofia ecocêntrica, precisamente em seu preâmbulo diz que: "Toda a forma de vida é única e merece ser respeitada, qualquer que seja a sua utilidade para o homem". Portanto, os animais são sujeitos de direitos subjetivos. ${ }^{10}$

Fica claro, então, que a ética aqui defendida não visa abrandar o sofrimento imposto aos animais, mas, partindo de uma conduta humana coerente, faz-se necessário que as vidas de tais indivíduos sejam consideradas relevantes, bem como seus interesses primordiais. Uma ética que tenha por base a conduta humana em todos os aspectos da sociedade deve prezar pela moralidade das ações humanas tendo em vista o 'outro' como um indivíduo também capaz de afetar-se por seus atos.

Deste modo, tal ética sugere aos indivíduos humanos que estes tenham por princípio, tendo em vista a moralidade intrínseca aos seus atos, a consideração das consequências de suas atitudes tanto para com a sociedade na qual estão inseridos quanto para com aqueles que compartilham deste mesmo ambiente, ou seja, todos os animais não-humanos, indivíduos sencientes e conscientes do mundo em que vivem, sendo críticos e reflexivos de maneira autônoma, e que desejem uma revolução antiespecista. Já há uma mudança social com o veganismo ${ }^{11}$ que é uma decisão política e moral, mas o primordial para uma revolução social aconteça é uma reeducação da sociedade como um todo.

\section{REFERÊNCIAS BIBLIOGRÁFICAS}

ACKEL FILHO, D. Direito dos animais. São Paulo: Themis, 2001.

10 Conforme refere Edna Cardozo Dias, "embora não possam ter identidade civil e ser registrados em cartório, são portadores de direitos inerentes à sua natureza de ser vivo e de indivíduos de uma determinada espécie. Se observarmos que os direitos de personalidade do ser humano Ihes pertencem como indivíduo, e se admitirmos que o direito à vida é imanente a tudo que vive, podemos concluir que os animais também possuem direitos de personalidade, como o direito á vida e ao não sofrimento. E tal como os juridicamente incapazes, seus direitos são garantidos por representatividade, tornando-se esses direitos deveres de todos os homens" (DIAS, E. C. A defesa dos animais e as conquistas legislativas do movimento de proteção animal no Brasil. Fórum de Direito Urbano e Ambiental, Belo Horizonte: Fórum, n. 17. set./out. 2004. pp. 1918-1926).

11 A novidade do veganismo não está apenas na sua bandeira de luta, a defesa dos direitos dos animais, está ainda nos modos como seus integrantes estão ressignificando valores e práticas que se confrontam com os padrões até então vigentes, ou melhor, com as fronteiras que estavam delineadas nessa oposição já discutida entre humanidadeanimalidade (ou ainda, entre autoconsciência e irracionalidade) (TRIGUEIRO, 2013). 
BROWN, R. Prejudice: Its social psychology. Chichester, UK: John Wiley \& Sons, 2010.

CARVALHO, G.F.S.S. A tutela jurídica dos animais: evolução histórica e conceitos contemporâneos. In: Congresso Brasileiro de Direito Ambiental, 21., 2016, São Paulo. Anais eletrônicos, 2016, v. II.

CAVALCA, R. F. O Direito Constitucional Internacional e os animais: a tutela dos animais como sujeitos de direitos. In: GARCIA, M; GAMBA, J. C. M; MONTAL, Z. M. C. (Coords.). Direito Constitucional Internacional. Curitiba: Juruá Editora, 2012.

ERNANDORENA, P. R. A mudança do Código Civil Francês estabelece um dever jurídico de fraternidade para com os animais? [Em linha]. III Congresso Nacional de Cominhão e Direito. [Consult. em: 30 Dez. 2020]. Disponível em: $<$ https://indd.adobe.com/view/035b834c-d090-4b8c-b019-a089308ccb7c262270>.

FELIPE, S. T. Produção de animais: a crítica filosófica abolicionista. [Em linha]. Texto da conferência proferida no 36 Congresso Vegetariano Mundial, realizado no Costão do Santinho, Florianópolis/SC, em 09.11.2004. [Consult. em 30 Dez. 2020]. Disponível em: <http://www.vegetarianismo.com.br/artigos>.

FERREIRA, A. C. B. S. G. A Proteção aos Animais e o Direito: o Status Jurídico dos Animais como Sujeitos de Direito. Curitiba: Juruá Editora, 2014.

GODINHO, A. M.; GODINHO, H. T. N. A controversa definição da natureza jurídica dos animais no estado socioambiental. [Em linha]. In: Seminário Internacional: Os Direitos Fundamentais no Estado Socioambiental, 10, 2011. Anais eletrônicos. Porto Alegre, RS: ESDM, 25 a 27 abr. 2011. p. 3. Disponível em: www.esdm.com.br/include\%5CdownloadSA.asp?file=downloa ds\%5CPaper\%20-\%20Natureza\%20Jur\%EDdica\%20dos\%20Animais_652011 1415 04.pdf. [Consult. em 30 Dez. 2020].

GOMES, O. Introdução ao Direito Civil. 19. ed. Rio de Janeiro: Forense, 2007.

GORDILHO, H.S.; TRAJANO, T. Habeas Corpus para os Grandes Primatas. Revista do Instituto do Direito Brasileiro da Faculdade de Direito da Universidade de Lisboa - RIDB. Ano 1, Lisboa, 2012.

JONAS, H. El principio de responsabilidad: ensayo de una ética para la civilización tecnológica. Barcelona: Editorial Herder, 1995. 
KELSEN, H. Teoria Geral do Direito e do Estado. Tradução de Luís Carlos Borges. 3. ed. São Paulo: Martins Fontes, 2000.

LOURENÇO, D. B. Direito dos Animais: fundamentação e novas perspectivas. Porto Alegre: Sergio Antonio Fabris, 2008.

MACHADO, P. A. L. Direito ambiental brasileiro. 24. ed. São Paulo: Malheiros, 2016.

REGAN, T. Jaulas Vazias: encarando o desafio dos direitos animais. Porto Alegre: Lugano, 2006.

RODRIGUES, D.T. 0 direito e os animais: uma abordagem ética, filosófica e normativa. 2. ed. Curitiba: Juruá, 2012.

SILVESTRE, G. F.; LORENZONI, I. L. A tutela jurídica material e processual da senciência animal no ordenamento jurídico brasileiro: análise da legislação e de decisões judiciais. RBDA, Salvador, v. 13, n. 01, p. 55-95, jan./abr. 2018.

SINGER, P. Libertação animal. Tradução de Maria de Fátima St. Aubyn. Porto: Via Óptima, 2008.

SINGER, P. Ética prática. São Paulo: Martins Fontes, 2006.

TRIGUEIRO, A. Consumo, ética e natureza: o veganismo e as interfaces de uma política de vida. Revista Internacional Interdisciplinar - INTERthesis, Florianópolis, v. 10, n. 1, jan./jun., 2013, p. 237-260. 